The Genus Youngia

By Ernest B. Babcock and G. Ledyard Stebbins, Jr. (Publication 484.) Pp. iii $+106+5$ plates. (Washington, D.C. : Carnegie Institution of Washington, 1937.) n.p.

$\mathrm{T}$

HE genus Youngia was deseribed more than a century ago by Cassini, but the characters on which the genus was based did not preclude the inclusion within it of species of several allied genera of the Cichoriece, and Cassini's species have long been merged in the genus Crepis. During his long study of the taxonomy and genetics of the latter genus, Prof. Babcock has repeatedly come in contact with certain Asiatic species invariably included in the genus Crepis which appeared generically distinct. For the reception of these species, the genus Youngia has been re-established and redefined.

Twenty-seven species, six of which are newly described, are included in the re-established genus, which is divided into six sections. The species mainly inhabit China, with extensions westwards to Ceylon, Kashmir and the Pamir-Altai cordillera and eastwards to Formosa and Japan. The monographic treatment includes discussions of the interrelationships of the sections and of the species within the sections, whilst admirably clear illustrations are given of all the species and subspecies. Two of the more widely distributed and polymorphic species which have been studied genetically show that variability is associated with polyploidy and parthenogenesis probably resulting from hybridization. This has led the authors to refrain from naming lesser variant forms, which are merely listed by number after the appropriate species. The major subspecific entities receive names but their citation as trinomials is to be regretted. The comparative scarcity of herbarium material consequent upon the remoteness of the localities at which many species occur will certainly lead to future additions to, and perhaps modifications of, the authors' arrangement; yet the work will remain of lasting value in having for the first time brought together and clarified the relationships of a group of species the previous systematic treatment of which has been unsatisfactory.

W. A. S.

\section{Modern Methods of Refining Lubricating Oils}

By Vladimir A. Kalichevsky. (American Chemical Society Monograph Series.) Pp. 235. (New York: Reinhold Publishing Corporation; London: Chapman and Hall, Ltd., 1938.) 30s. net.

IN the United States, the older cruder methods of refining are fast becoming obsolete and are being everywhere replaced by solvent processes, which have the great merit of removing the unsatisfactory asphaltic constituents generally termed naphthenics. In addition, the systematic use of additives for improving certain particular characteristics is beginning to become of commercial importance. The time is ripe for the description and discussion of these new methods of refining and the general principles which underlie them : it is now provided in handy book form by Mr. V. A. Kalichevsky, as one of the well-known American Chemical Society series of monographs.

The solvent refining processes represent a great advance in chemical engineering and are characterized indeed by considerable daring as, for example, in the use of liquid propane as a solvent. They are continuous and even involve the use of two solvents which carry the separated constituents of the crude oil in opposite directions.

Besides removing the asphaltic constituents, a second separate solvent treatment is used to remove the high melting waxes, so that the final products are straw-coloured fluid oils which do not thicken even at the low temperatures experienced in high flying.

The book tells the full story in a practical manner and should be welcomed by a large number of those engaged in the lubricating industry.

E. F. A.

\section{The Children's Play Centre :}

its Psychological Value and its Place in the Training of Teachers. By D. E. M. Gardner. (Contributions to Modern Education.) Pp. xv +143 . (London : Methuen and Co., Ltd., 1937.) 3s. 6d. net.

WE refer to this book, not so much because of its detailed account of the working of a play centre, a subject which is somewhat outside our province, as because we think it exemplifies a really scientific approach to the problems of child-study. As Dr. Susan Isaacs points out in her foreword, young teachers find it difficult to connect the generalizations of their text-books of psychology with their own experience, or with the actual children they have to face in the schools. In fact, they begin at the wrong end. They are led to disobey the accepted rules of pedagogic and of scientific method. From this mistake the play centre, where children can be observed under the most natural conditions, provides a way of escape. Let the young teacher begin there, and the text-books will convey far more meaning than they usually do at present.

The Observer's Book of British Wild Animals

Compiled by W. J. Stokoe. Pp. 224. (London : Frederick Warne and Co., Ltd., 1938.) 2s. 6d. net.

7 HIS is the fifth of a series of handy pocket books 1 (see also Nature, 141, 351; 1938), one of their merits being that they actually are pocket books, $5 \frac{1}{2}$ in. by $3 \frac{1}{2}$ in., and therefore convenient to carry on nature rambles. In this volume, sixty-nine species of British animals are described, and the text is illustrated by seventy-two illustrations, forty-six of which are in colour. Naturally, most of the book is devoted to mammals, but the few British reptiles and amphibians are also described. The term 'animals' in the title is used in the common, but erroneous, sense. However, so far, birds and butterflies have been dealt with in previous volumes. Thus, the present volume concludes in this series consideration of all terrestrial vertebrates. To those interested in the natural history of the countryside, this "Observer's Pocket Series" can be strongly recommended. 